\title{
Cortisol-binding globulin is important in the interpretation of dynamic tests of the hypothalamic-pituitary-adrenal axis
}

\author{
W S Dhillo, W M Kong, C W Le Roux, J Alaghband-Zadeh ${ }^{1}$, J Jones ${ }^{1}$, G Carter ${ }^{1}$, N Mendoza ${ }^{2}$, K Meeran and
} D O'Shea

Departments of Endocrinology, ${ }^{1}$ Clinical Chemistry and ${ }^{2}$ Neurosurgery, Imperial College School of Medicine, Charing Cross and Hammersmith Hospital Sites, London W6 8RF, UK

(Correspondence should be addressed to W S Dhillo, Department of Endocrinology, Hammersmith Hospital, Du Cane Road, London W12 ONN, UK; Email: w.dhillo@ic.ac.uk)

(W S Dhillo and W M Kong contributed equally to the work in this paper)

\begin{abstract}
Objective: Assessment of the hypothalamic-pituitary-adrenal (HPA) axis relies on the interpretation of serum (total) cortisol in response to dynamic tests of the HPA axis. Most cortisol is bound to cortisolbinding globulin (CBG) and serum total cortisol levels are significantly affected by variation in CBG. We hypothesised that CBG variation significantly affects interpretation of dynamic tests of the HPA axis.

Design: We investigated the effect of CBG variation on the outcome of the $250 \mu \mathrm{g}$ short Synacthen test (SST) in 30 healthy adults.

Methods: Blood was sampled at time -30 , 0 (at which point Synacthen was given) and $+30 \mathrm{~min}$. $\mathrm{CBG}$ and total cortisol were measured at each time-point. Integrity of the HPA axis was confirmed by measurement of urine cortisol.

Results: We found that CBG varied significantly within individuals, falling from $51 \pm 3.4$ to $43 \pm$ $3.2 \mu \mathrm{g} / \mathrm{ml}(P<0.0001)$ on changing from standing to lying. Total cortisol levels strongly correlated with CBG $(r=0.88, P<0.0001)$. Thirteen subjects had a $+30 \mathrm{~min}$ total cortisol $<550 \mathrm{nmol} / \mathrm{l}$. In these subjects, the CBG levels at each time-point were significantly lower compared with subjects who had a $+30 \mathrm{~min}$ total cortisol of $>550 \mathrm{nmol} / \mathrm{l}(P<0.05)$. To correct for variation in CBG we calculated the total cortisol:CBG ratio and found no significant difference in the +30 min ratio between these two groups.

Conclusion: CBG varies significantly within and between individuals. This is accompanied by changes in serum total cortisol large enough to affect the outcome of an SST and, by implication, other tests of the HPA axis.
\end{abstract}

European Journal of Endocrinology 146 231-235

\section{Introduction}

Accurate assessment of the hypothalamic-pituitaryadrenal (HPA) axis is essential in the management of patients with pituitary disease and in patients being withdrawn from long-term glucocorticoid therapy. Failure to recognise secondary adrenal insufficiency can have potentially life-threatening consequences whilst unnecessary hydrocortisone replacement therapy may cause significant morbidity in terms of glucocorticoid side-effects. However, the optimal method for the assessment of the HPA axis remains controversial (1, 2 ). The two most commonly used tests are the insulin tolerance test (ITT) and the $250 \mu \mathrm{g}$ short Synacthen test (SST). Clinical decisions regarding long-term hydrocortisone replacement are based on the results of these tests. Their interpretation relies on measured serum total cortisol levels in response to stimulation, as an indicator of an individual's HPA axis reserve. Over $80 \%$ of serum total cortisol is bound, predominantly to cortisol-binding globulin (CBG) (3). This is analogous to the situation with total thyroxine and thyroninebinding globulin (TBG). Variation in TBG affects total thyroxine levels. However, although cortisol assays measure total cortisol, CBG levels are not considered in the interpretation of cortisol results.

In a recent study, it was found that serum total cortisol levels did not correlate with the cortisol production rates $(r=0.18)$ unless differences in CBG were corrected for. The serum total cortisol measurement was likely to underestimate cortisol production in subjects with lower CBG levels (4). These findings are likely to 
be important for the correct interpretation of cortisol measurements in tests of the HPA axis. Unlike serum total cortisol, urine cortisol is not affected by variation in CBG. We have previously demonstrated that the increment in urinary cortisol levels between midnight and morning (cortisol/creatinine (Cort/Cr) increment) is an accurate alternative for assessment of the HPA axis (5).

The $250 \mu \mathrm{g}$ SST is widely used for the assessment of the HPA axis (6-8). We hypothesised that CBG variation is clinically relevant in the interpretation of serum total cortisol results in dynamic function tests of the HPA axis. To investigate this, we performed the SST in 30 normal individuals and examined their serum total cortisol responses with respect to their CBG levels. We assessed the integrity of the HPA axis in the subjects by measuring their urinary Cort/Cr increment.

\section{Subjects and methods}

\section{Subjects}

Thirty healthy, adult volunteers were recruited (16 male and 14 female). The mean age was 35.2 46.4 years. Oestrogen treatment was noted as oestrogens are known to increase CBG levels (9). Subjects were excluded if they had a history of other steroid use, adrenal or pituitary disease.

\section{Short Synacthen test}

A $250 \mu \mathrm{g}$ SST was performed between 0800 and $0900 \mathrm{~h}$. At each sampling point, blood was taken for cortisol and CBG. On arrival, subjects were made recumbent and remained so throughout the test period. A 21 gauge cannula was inserted in the antecubital fossa and a blood sample taken (time, $-30 \mathrm{~min})$. The cannula was kept patent by flushing with a single bolus of $5 \mathrm{ml} 0.9 \%$ saline. Thirty minutes later (time, $0 \mathrm{~min}$ ), having discarded $10 \mathrm{ml}$ blood, a further sample was taken for total cortisol and CBG, and $250 \mu \mathrm{g}$ Synacthen (Novartis, Frimley, Surrey, UK) was injected through the same cannula, followed by a $5 \mathrm{ml}$ saline flush. A final sample was taken $30 \mathrm{~min}$ later (time, $+30 \mathrm{~min}$ ), again having discarded $10 \mathrm{ml}$ blood. The study received approval from the local ethics committee (Riverside Research Ethics Committee, number 1911).

\section{Cortisol and CBG measurements}

Serum total cortisol was assayed by an automated ELISA technique (ES700; Roche Diagnostics, Lewes, E Sussex, UK). External quality assessment (UKNEQAS) of this serum cortisol assay showed that mean total cortisol measurements were within 5\% of the national average (All Laboratory Trimmed Mean). CBG assays were performed using the Biosource radioimmunoassay (RIA; Lifescreen, Watford, Herts, UK) (normal range: males $27.1-52.3 \mu \mathrm{g} / \mathrm{ml}$, females $31.0-53.4 \mu \mathrm{g} / \mathrm{ml}$ and oestrogen-treated females $64.4-116 \mu \mathrm{g} / \mathrm{ml}$ ). The intra-assay coefficient of variation was $7.7 \%$ and $3.8 \%$ at CBG levels of 33.1 and $62.2 \mu \mathrm{g} / \mathrm{ml}$ respectively.

\section{Urinary Cort/Cr increment}

In our subjects, we assessed the integrity of the HPA axis by performing the SST and the urinary Cort/Cr increment (5), and compared their results.

The midnight to morning urinary Cort/Cr increment was measured as previously described (5). Briefly, subjects provided double-voided urine samples (subjects were instructed to empty their bladders $1 \mathrm{~h}$ before collecting the samples) at midnight and at their normal waking time. Cortisol and creatinine were measured in the urine samples. To correct for differences in glomerular filtration rate, the Cort/Cr ratio was calculated. The Cort/Cr increment was defined as the morning Cort/Cr minus the midnight Cort/Cr. A Cort/Cr increment of 9 or greater indicates an intact HPA axis (5).

Urinary free cortisol was measured by a competitive RIA on non-extracted urine (Orion Diagnostica, Turku, Finland). The sensitivity of this assay was $5 \mathrm{nmol} / \mathrm{l}$ and the intra- and interassay variations were $7.8 \%$ and $14 \%$ respectively. Urinary creatinine was measured by a kinetic Jaffé procedure using a Hitachi 747 analyser (Roche Diagnostics) according to the manufacturer's instructions.

\section{Statistical analysis}

Group values for total cortisol and CBG are given as the mean \pm S.E.M. Comparison of total cortisol and CBG levels within subjects, at the different time-points, was made by paired Student's t-test. Differences in total cortisol and CBG between subjects were compared by unpaired Student's t-test. The cortisol:CBG (Cort/CBG) ratio was compared between subjects using the Mann-Whitney U test. The Pearson product moment analysis was used to calculate the correlation between total cortisol and CBG levels. Significance was taken as $P<0.05$.

\section{Results}

\section{CBG}

There was a highly significant $16 \%$ fall in CBG in all subjects between $-30 \mathrm{~min}$ and $0 \mathrm{~min}(51 \pm 3.4 \mu \mathrm{g} / \mathrm{ml}$ to $43 \pm 3.2 \mu \mathrm{g} / \mathrm{ml}, \quad P<0.0001)$. The fall in $\mathrm{CBG}$ between -30 and 0 min was accompanied by a comparable $18 \%$ fall in cortisol $(475 \pm 47 \mathrm{nmol} / \mathrm{l}$ to $386 \pm 35 \mathrm{nmol} / \mathrm{l}, P<0.0001)$. The CBG level did not change between 0 and $+30 \mathrm{~min}(43 \pm 3.2 \mu \mathrm{g} / \mathrm{ml}$ vs $44 \pm 3.1 \mu \mathrm{g} / \mathrm{ml}$ ). There was a highly significant 


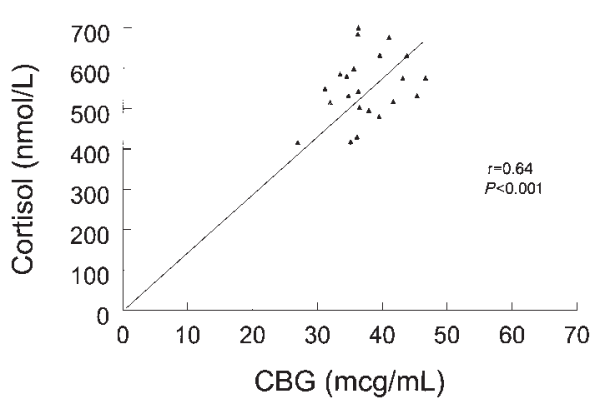

Figure 1 Cortisol variation according to $\mathrm{CBG}$ at time $+30 \mathrm{~min}$. Subjects were given $250 \mu \mathrm{g}$ Synacthen at time $0 \mathrm{~min}$. Data represent cortisol and CBG values for subjects not receiving oestrogen treatment at time $+30 \mathrm{~min}$.

correlation between $\mathrm{CBG}$ and cortisol values at $-30 \mathrm{~min}$ and $0 \mathrm{~min}(r=0.88, P<0.0001)$ and at $+30 \min (r=0.64, P<0.001$, Fig. 1$)$.

\section{Relationship between CBG and cortisol response to SST}

Five subjects were taking oestrogen-containing products. In view of the significant effect of oestrogens on CBG and therefore cortisol (9), subjects on oestrogen were excluded from the analysis of the SST results. Tables 1 and 2 summarise the SST results for each of the 25 . A $+30 \mathrm{~min}$ serum total cortisol of $550 \mathrm{nmol} / \mathrm{l}$ or above in response to an SST is widely used to indicate an intact HPA axis (8). Thirteen of the subjects had a $+30 \mathrm{~min}$ total cortisol of $<550 \mathrm{nmol} / \mathrm{l}$. At each of the three time-points the CBG levels were significantly higher in the subjects with a +30 min total cortisol of $>550 \mathrm{nmol} / \mathrm{l}$ compared with those who had a $+30 \mathrm{~min}$ total cortisol of $<550 \mathrm{nmol} / \mathrm{l}$ (Table 3). To correct for variation in CBG we calculated the Cort/CBG ratio. In contrast to the serum total cortisol results, there was no difference in the $+30 \mathrm{~min}$ Cort $/ \mathrm{CBG}$ between the subjects whose +30 min total cortisol was $>550 \mathrm{nmol} / \mathrm{l}$ (Cort/CBG ratio 12-19) compared with those subjects whose +30 min total cortisol was $<550 \mathrm{nmol} / \mathrm{l}$ (Cort/CBG ratio 12-18) (Tables 1 and 2).

\section{Urinary Cort/Cr increment}

Eighteen subjects performed urine collections, of whom nine had a $+30 \mathrm{~min}$ total cortisol of $>550 \mathrm{nmol} / \mathrm{l}$ and nine had a $+30 \mathrm{~min}$ total cortisol of $<550 \mathrm{nmol} / \mathrm{l}$. However, all 18 subjects had an intact HPA axis with a urinary Cort/Cr increment of 9 or greater.

\section{Discussion}

Many physicians use the $250 \mu \mathrm{g}$ SST as the first-line test for the assessment of the HPA axis $(6-8)$ with an estimated three million SSTs being performed worldwide each year (5). However, the SST has been criticised for its limited concordance with the ITT. In addition to the well-recognised problem of false passes (i.e. people who pass their SST but fail their ITT), there is also a substantial false failure rate (i.e. people who fail their SST but pass their ITT). This false failure rate can be as high as 35\% (10).

The SST relies on serum total cortisol responses. A large proportion of serum total cortisol is bound to CBG (80-90\%). Thus, serum total cortisol levels are affected by variation in CBG. It has been shown that the changes in serum total cortisol levels do not correlate with cortisol production rates unless differences in CBG are corrected for (4). However, CBG is not routinely considered in the interpretation of total cortisol measurements. Our data suggest that CBG is important for the correct interpretation of dynamic tests of the HPA axis.

Table 1 Results of subjects (M, male; F, female) with +30 min cortisol $<550 \mathrm{nmol} / /$.

\begin{tabular}{|c|c|c|c|c|c|c|c|c|c|}
\hline \multirow[b]{2}{*}{$\begin{array}{l}\text { M/F } \\
\text { (age) }\end{array}$} & \multicolumn{3}{|c|}{$-30 \mathrm{~min}$} & \multicolumn{3}{|c|}{$0 \mathrm{~min}$} & \multicolumn{3}{|c|}{$+30 \mathrm{~min}$} \\
\hline & $\begin{array}{l}\text { Cortisol } \\
(\mathrm{nmol} / \mathrm{l})\end{array}$ & $\begin{array}{c}\text { CBG } \\
(\mu \mathrm{g} / \mathrm{ml})\end{array}$ & Cort/CBG ratio & $\begin{array}{l}\text { Cortisol } \\
(\mathrm{nmol} / \mathrm{l})\end{array}$ & $\begin{array}{c}\text { CBG } \\
(\mu \mathrm{g} / \mathrm{ml})\end{array}$ & Cort/CBG ratio & $\begin{array}{l}\text { Cortisol } \\
(\mathrm{nmol} / \mathrm{l})\end{array}$ & $\begin{array}{c}\text { CBG } \\
(\mu \mathrm{g} / \mathrm{ml})\end{array}$ & Cort/CBG ratio \\
\hline $\mathrm{M} / 27$ & 407 & 36.5 & 11 & 279 & 26.7 & 10 & 416 & 26.9 & 15 \\
\hline $\mathrm{M} / 29$ & 328 & 44.6 & 7 & 247 & 35.1 & 7 & 418 & 35.0 & 12 \\
\hline $\mathrm{F} / 43$ & 307 & 42.3 & 7 & 263 & 33.6 & 8 & 430 & 36 & 12 \\
\hline F/63 & 381 & 45.4 & 8 & 280 & 37.5 & 8 & 496 & 37.8 & 13 \\
\hline $\mathrm{M} / 33$ & 356 & 46.1 & 8 & 257 & 34.6 & 7 & 503 & 36.4 & 14 \\
\hline $\mathrm{F} / 51$ & 325 & 37.1 & 9 & 218 & 31.4 & 7 & 516 & 31.9 & 16 \\
\hline $\mathrm{M} / 31$ & 228 & 41.8 & 6 & 222 & 39.2 & 6 & 518 & 41.6 & 12 \\
\hline M/36 & 396 & 51.6 & 8 & 306 & 44.6 & 7 & 532 & 45 & 12 \\
\hline $\mathrm{F} / 24$ & 471 & 41.8 & 11 & 351 & 36.4 & 10 & 533 & 34.7 & 15 \\
\hline $\mathrm{M} / 24$ & 407 & 42.6 & 10 & 342 & 34.5 & 10 & 542 & 36.2 & 15 \\
\hline M/29 & 419 & 40.1 & 10 & 358 & 30.5 & 12 & 543 & 31 & 18 \\
\hline Mean & 352 & 42.2 & 8 & 275 & 34.8 & 8 & 498 & 35.6 & 14 \\
\hline
\end{tabular}


Table 2 Results of subjects (M, male; F, female) with a $+30 \mathrm{~min}$ cortisol of $550 \mathrm{nmol} / \mathrm{l}$ or above.

\begin{tabular}{|c|c|c|c|c|c|c|c|c|c|}
\hline \multirow[b]{2}{*}{$\begin{array}{l}\text { M/F } \\
\text { (age) }\end{array}$} & \multicolumn{3}{|c|}{$-30 \mathrm{~min}$} & \multicolumn{3}{|c|}{$0 \mathrm{~min}$} & \multicolumn{3}{|c|}{$+30 \mathrm{~min}$} \\
\hline & $\begin{array}{l}\text { Cortisol } \\
\text { (nmol/l) }\end{array}$ & $\begin{array}{c}\text { CBG } \\
(\mu \mathrm{g} / \mathrm{ml})\end{array}$ & Cort/CBG ratio & $\begin{array}{l}\text { Cortisol } \\
\text { (nmol/l) }\end{array}$ & $\begin{array}{l}\text { CBG } \\
(\mu \mathrm{g} / \mathrm{ml})\end{array}$ & Cort/CBG ratio & $\begin{array}{l}\text { Cortisol } \\
\text { (nmol/l) }\end{array}$ & $\begin{array}{c}\text { CBG } \\
(\mu \mathrm{g} / \mathrm{ml})\end{array}$ & Cort/CBG ratio \\
\hline $\mathrm{M} / 24$ & 428 & 52 & 8 & 396 & 47.1 & 8 & 576 & 46.6 & 12 \\
\hline $\mathrm{F} / 23$ & 485 & 47.9 & 10 & 385 & 42.7 & 9 & 576 & 43.1 & 13 \\
\hline M/22 & 538 & 44.7 & 12 & 416 & 33.6 & 12 & 580 & 34.4 & 17 \\
\hline F/69 & 422 & 41.3 & 10 & 321 & 32.3 & 10 & 585 & 33.4 & 18 \\
\hline $\mathrm{M} / 45$ & 296 & 42.3 & 7 & 268 & 35.2 & 8 & 599 & 35.5 & 17 \\
\hline M/38 & 596 & 50.2 & 12 & 493 & 45.3 & 11 & 631 & 43.7 & 14 \\
\hline M/32 & 428 & 40.1 & 11 & 365 & 38.6 & 9 & 632 & 39.5 & 16 \\
\hline $\mathrm{M} / 75$ & 334 & 53.5 & 6 & 272 & 42.1 & 6 & 676 & 40.9 & 17 \\
\hline $\mathrm{M} / 59$ & 273 & 39.8 & 7 & 379 & 35 & 11 & 684 & 36.1 & 19 \\
\hline M/19 & 481 & 40.1 & 12 & 450 & 35.4 & 13 & 700 & 36.2 & 19 \\
\hline F/39 & 675 & 52.4 & 13 & 610 & 45.7 & 13 & 792 & 45.5 & 17 \\
\hline$M / 24$ & 741 & 71 & 10 & 576 & 66.3 & 9 & 833 & 66.3 & 13 \\
\hline Mean & 475 & 47.9 & 10 & 411 & 41.6 & 10 & 655 & 41.8 & 16 \\
\hline
\end{tabular}

CBG levels are known to vary between individuals and this was seen in our study. Our results showed that $\mathrm{CBG}$ also varied significantly within individuals. The dramatic fall in CBG levels between -30 and 0 min was an unexpected finding. The only change in the subjects between -30 and 0 min was that they had gone from a standing to a lying posture. Thus, this fall in CBG between -30 and 0 min presumably reflects volume redistribution when changing from standing to lying. This would be analogous to the well-recognised fall in serum albumin which occurs from standing to lying which, in turn, results in a fall in serum calcium (11). As CBG levels strongly correlate with serum total cortisol levels, this fall in CBG is likely to be highly relevant in the interpretation of total cortisol measurements.

A $+30 \mathrm{~min}$ serum total cortisol of $550 \mathrm{nmol} / \mathrm{l}$ or above in response to an SST is widely used to indicate an intact HPA axis (8). This +30 min total cortisol cut-off level gives a concordance with the ITT of approximately $64 \%$ (10). Thirteen of the healthy volunteers had a $+30 \mathrm{~min}$ total cortisol of $<550 \mathrm{nmol} / \mathrm{l}$, but were well with no symptoms to suggest HPA insufficiency. Furthermore, nine of these subjects provided urine samples and their urine $\mathrm{Cort} / \mathrm{Cr}$ increment indicated that they had an intact HPA axis. It could be argued that this high false failure rate (i.e. subjects with a normal HPA axis who had a +30 min total cortisol of $<550 \mathrm{nmol} / \mathrm{l}$ ) was due to the cortisol cut-off value for interpreting the SST being too high. However, five of the healthy volunteers had a +30 min total cortisol of $<500 \mathrm{nmol} / \mathrm{l}$ (Table 1). Other groups have shown a similar high false failure rate with the SST $(10,12)$ when it was used to assess the HPA axis. This can partly be explained by the fact that the +30 min total cortisol cut-off value used for the SST in the assessment of the HPA axis is the total cortisol value that gives the best concordance with the ITT, and is not derived from the normal range (mean \pm 2 S.D.) for the SST (which in a recent paper (10) was found to be $392-864 \mathrm{nmol} / \mathrm{l})$. Few physicians would accept a total cortisol of $392 \mathrm{nmol} / \mathrm{l}$ as an adequate HPA reserve. Recent work has suggested that differences in serum total cortisol concentrations can result from the use of different assay methods (13, 14). Such differences would not explain our results. The total cortisol assay used in this study is within $5 \%$ of the national mean. Importantly, neither laboratory assay variation nor the choice of cortisol cut-off value chosen can explain our key finding: that the subjects with a $+30 \mathrm{~min}$ total cortisol of $<550 \mathrm{nmol} / \mathrm{l}$ had significantly lower CBG levels than those with a

Table 3 CBG values at $-30,0$ and +30 min of the $250 \mu \mathrm{g}$ SST. Subjects have been grouped according to whether their +30 min post Syancthen cortisol level was greater or less than $550 \mathrm{nmol} / \mathrm{l}$.

\begin{tabular}{lccr}
\hline & \multicolumn{2}{c}{ CBG $(\mu \mathrm{g} / \mathrm{ml})$} & \\
\cline { 2 - 3 } Time post Synacthen & $\begin{array}{c}\text { Subjects with }+30 \mathrm{~min} \\
\text { cortisol }>550 \mathrm{nmol}\end{array}$ & $\begin{array}{c}\text { Subjects with }+30 \mathrm{~min} \\
\text { cortisol }<550 \mathrm{nmol}\end{array}$ & $\boldsymbol{P}$ value \\
\hline$-30 \mathrm{~min}$ & $48 \pm 2.6$ & $42 \pm 1.1$ & $<0.05$ \\
0 min & $42 \pm 2.7$ & $35 \pm 1.3$ & $<0.05$ \\
+30 min & $42 \pm 2.6$ & $36 \pm 1.4$ & $<0.05$ \\
\hline
\end{tabular}

Values are means \pm S.E.M. 
$+30 \mathrm{~min}$ total cortisol of $>550 \mathrm{nmol} / \mathrm{l}$. This strongly suggests that whatever +30 min total cortisol cut-off value is chosen for a pass on the SST, the CBG level is a major and independent determinant in the clinical outcome of the SST.

All of the subjects were normal healthy volunteers and had urine Cort/Cr increments which indicated intact HPA axes. There is no association between adrenal failure and low CBG levels $(15,16)$. This suggests that the 13 subjects who had a +30 min total cortisol of $<550 \mathrm{nmol} / \mathrm{l}$ had low total cortisol values because of their low CBG levels. To correct for variation in CBG we calculated the Cort/CBG ratio, which has been shown to correlate with free cortisol $(17,18)$. Whereas there was a significant difference in the +30 min total cortisol values between subjects with a $+30 \mathrm{~min}$ total cortisol of $>550 \mathrm{nmol} / \mathrm{l}$ compared with those with a $+30 \mathrm{~min}$ total cortisol of $<550 \mathrm{nmol} / \mathrm{l}$, there was no difference in their Cort/CBG ratios. This suggests that the free cortisol responses to Synacthen in all subjects were normal. Use of the Cort/CBG ratio, rather than serum total cortisol levels alone, may be more appropriate in the interpretation of dynamic tests of the HPA axis.

In summary, we have shown that serum total cortisol correlates with $\mathrm{CBG}$, and that $\mathrm{CBG}$ varies significantly between individuals and within individuals between standing and lying. This normal variation in CBG is accompanied by changes in serum total cortisol, which can be large enough to affect the outcome of the SST and, by implication, other tests dependent on measured serum total cortisol. We have only examined the effect of CBG variation on the SST. The effect of CBG variation on the outcome of an ITT is clearly an important area that warrants further investigation. More importantly, our work needs to be extended to patients with pituitary disease and patients on steroid therapy. Nonetheless, our data suggest that serum cortisol levels should be interpreted with reference to the CBG.

\section{References}

1 Davies MJ \& Howlett TA. A survey of the current methods used in the UK to assess pituitary function. Journal of the Royal Society of Medicine 199689 159-164.

2 Streeten DH. What test for hypothalamic-pituitary-adrenocortical insufficiency? Lancet $1999 \mathbf{3 5 4} 179-180$.

3 Brien TG. Human corticosteroid binding globulin. Clinical Endocrinology $1981 \mathbf{1 4} 193-212$.
4 Bright GM \& Darmaun D. Corticosteroid-binding globulin modulates cortisol concentration responses to a given production rate. Journal of Clinical Endocrinology and Metabolism $1995 \mathbf{8 0}$ $764-769$.

5 Kong WM, Alaghband ZJ, Jones J, Carter G \& O'Shea D. The midnight to morning urinary cortisol increment is an accurate, noninvasive method for assessment of the hypothalamicpituitary-adrenal axis. Journal of Clinical Endocrinology and Metabolism 199984 3093-3098.

6 Stewart PM, Corrie J, Seckl JR, Edwards CR \& Padfield PL. A rational approach for assessing the hypothalamo-pituitaryadrenal axis. Lancet 1988 I $1208-1210$.

7 Grinspoon SK \& Biller BM. Clinical review 62: Laboratory assessment of adrenal insufficiency. Journal of Clinical Endocrinology and Metabolism 199479 923-931.

8 Clayton RN. Short Synacthen test versus insulin stress test for assessment of the hypothalamo-pituitary-adrenal axis: controversy revisited [comment]. Clinical Endocrinology $1996 \mathbf{4 4}$ 147-149.

9 Musa BU, Doe RP \& Seal US. Serum protein alterations produced in women by synthetic estrogens. Journal of Clinical Endocrinology and Metabolism 196727 1463-1469.

10 Hurel SJ, Thompson CJ, Watson MJ, Harris MM, Baylis PH \& Kendall TP. The short Synacthen and insulin stress tests in the assessment of the hypothalamic-pituitary-adrenal axis. Clinical Endocrinology $1996 \mathbf{4 4} 141-146$.

11 Marshall WJ \& Bangert SK. The acquisition of biochemical data. In Clinical Biochemistry and Metabolic Clinical Aspects, ch. 2, p 10. Eds WJ Marshall \& SK Bangert. New York: Churchill Livingstone, Medical Division of Pearson Professional Limited, 2000.

12 Kane KF, Emery P, Sheppard MC \& Stewart PM. Assessing the hypothalamo-pituitary-adrenal axis in patients on long-term glucocorticoid therapy: the short synacthen versus the insulin tolerance test. Quarterly Journal of Medicine $1995 \mathbf{8 8} 263-267$.

13 Clark PM, Neylon I, Raggatt PR, Sheppard MC \& Stewart PM. Defining the normal cortisol response to the short Synacthen test: implications for the investigation of hypothalamic-pituitary disorders. Clinical Endocrinology 199849 287-292.

14 Stewart PM \& Clark PM. The short Synacthen test: is less best? (Commentary). Clinical Endocrinology 199950 151-152.

15 De-Moor P, Steeno O, Brosens I \& Hendrikx A. Data on transcortin activity in human plasma as studied by gel filtration. Journal of Clinical Endocrinology and Metabolism 196626 71-78.

16 Murray D. Cortisol binding to plasma proteins in man in health, stress and at death. Journal of Endocrinology 196739 571-591.

17 Coolens JL, Van Baelen H \& Heyns W. Clinical use of unbound plasma cortisol as calculated from total cortisol and corticosteroid-binding globulin. Journal of Steroid Biochemistry 198726 197-202.

18 Bonte HA, van den Hoven RJ, van der Sluijs Veer G \& Vermes I. The use of free cortisol index for laboratory assessment of pituitary-adrenal function. Clinical Chemistry and Laboratory Medicine $199937127-132$.

Received 27 June 2001

Accepted 23 October 2001 